\title{
Nickel Nitride Particles Supported on 2D Activated Graphene-Black Phosphorus Heterostructure: An Efficient Electrocatalyst for the Oxygen Evolution Reaction
}

\author{
Xiao Wang, Qiaoxia Li, Penghui Shi, Jinchen Fan,* Yulin Min,* and Qunjie Xu*
}

Hydrogen is regarded as the most promising green clean energy in the 21st century. Developing the highly efficient and low-cost electrocatalysts for oxygen evolution reaction (OER) is of great concern for the hydrogen industry. In the water electrolyzed reaction, the overpotential and the kinetics are the main hurdles for OER. Therefore, an efficient and durable oxygen evolution reaction electrocatalyst is required. In this study, an activated graphene (AG)-black phosphorus (BP) nanosheets hybrid is fabricated for supporting $\mathrm{Ni}_{3} \mathrm{~N}$ particles ( $\left.\mathrm{Ni}_{3} \mathrm{~N} / \mathrm{BP}-\mathrm{AG}\right)$ in the application of OER. The $\mathrm{Ni}_{3} \mathrm{~N}$ particles are combined with the BP-AG heterostructure via facile mechanical ball milling under argon protection. The synthesized $\mathrm{Ni}_{3} \mathrm{~N} / \mathrm{BP}$-AG shows excellent catalytic performance toward the OER, demanding the overpotential of $233 \mathrm{mV}$ for a current density of $10 \mathrm{~mA} \mathrm{~cm}^{-2}$ with a Tafel slope of $42 \mathrm{mV} \mathrm{dec}^{-1}$. The $\mathrm{Ni}_{3} \mathrm{~N} / \mathrm{BP}-\mathrm{AG}$ catalysts also show remarkable stability with a retention rate of the current density of about $86.4 \%$ after measuring for $10000 \mathrm{~s}$ in potentiostatic mode.

electron redox process. ${ }^{[2]}$ Electrocatalysts as key components play important roles in OER. At present, Ir/Ru-based catalysts are deemed as the top-priority selection for OER. Nevertheless, the high cost and shortage of resources seriously hinder their large-scale application. ${ }^{[3]}$ The probe of noble-metal-free electrocatalysts is born at the right moment.

Graphene as a 2D crystal has received great attention due to its excellent electrical, optical, and mechanical properties. Owing to its large surface area and high electro conductivity, graphene is constantly considered as ideal building blocks for metal or nonmetal catalysts. ${ }^{[4]}$ Mai and co-workers ${ }^{[5]}$ developed graphene as the supports for the metal-organic framework derived carbon-confined $\mathrm{Ni}_{2} \mathrm{P}$ nanocrystals. The catalysts show superior

\section{Introduction}

Along with the development of society, the gradual exhausted of fossil fuels has become a major puzzle. The problem has brought the intense pursuit of highly efficient and sustainable energy conversion and storage means, among which electrolyzed water for hydrogen has been regarded as one of the most capable approaches. ${ }^{[1]}$ As a half reaction of electrocatalytic water splitting, oxygen evolution reaction (OER) usually demands around $1.8-2.0 \mathrm{~V}$ to overcome the reaction obstacle which is mainly related to the dull transfer rate generated by complex

X. Wang, Prof. Q. Li, Prof. P. Shi, Prof. J. Fan, Prof. Y. Min, Prof. Q. Xu Shanghai Key Laboratory of Materials Protection

and Advanced Materials in Electric Power

Shanghai University of Electric Power

Shanghai 200090, P. R. China

E-mail: Jinchen.fan@shiep.edu.cn; minyulin@shiep.edu.cn;

xuqunjie@shiep.edu.cn

Prof. J. Fan, Prof. Y. Min, Prof. Q. Xu

Shanghai Institute of Pollution Control and Ecological Security

Shanghai 200092, P. R. China

Prof. J. Fan

Department of Chemical Engineering and Biointerfaces Institute University of Michigan

Ann Arbor, MI 48109, USA

The ORCID identification number(s) for the author(s) of this article can be found under https://doi.org/10.1002/smll.201901530.

DOI: $10.1002 / \mathrm{smll} .201901530$ electrocatalytic performance than that of the commercial $\mathrm{IrO}_{2}$. Ishihara and co-workers ${ }^{[6]}$ prepared nitrogen-doped graphene to prop up $\mathrm{Ni}-\mathrm{Fe}$ nitride nanoplates for reversible OER. Chen and co-workers ${ }^{[7]}$ exploited nitrogen and sulfur-codoped graphene composites with $\mathrm{Co}_{9} \mathrm{~S}_{8}$, which can work for $\mathrm{H}_{2}$ and $\mathrm{O}_{2}$ in the same electrolyte. In the past decades, the researcher explored various types of graphene-supported hybrids for OER to take the place of noble metal catalysts. On this basis, 2D/2D heterojunctions which possess rich, active sites, low intrinsic resistance, and convenient transport path ${ }^{[8]}$ have been investigated simultaneously.

In this regard, the other graphene-like 2D materials have been diffusely inspected both experimentally and theoretically. However, due to the no direct bandgap of graphene, the logic switching of semiconductors cannot be realized, which restricts the application of graphene in the semiconductor field and photovoltaic field. However, the low mobility of 2D transitional metal dichalcogenides (TMDs), such as $\mathrm{MoS}_{2}$ and $\mathrm{WS}_{2}$, with direct bandgap also limits their application in the territory of electronics. ${ }^{[9]}$ Therefore, it is especially important to find $2 \mathrm{D}$ materials with suitable bandgaps and great conductive capability. Fortunately, black phosphorus (BP) comes to light which pulls double duty.

Similar to graphene, black phosphorus is a stabilized crystal with the corrugated layer structure. Because of its combination of van der Waals forces, the black phosphorus can be peeled easily off into single or few layers. ${ }^{[10]}$ In the monoatomic layer, each phosphorus atom forms the pleated honeycomb 
structure, which consists of the covalent bond with the adjacent three phosphorus atoms by $\mathrm{sp}^{3}$ hybridization. Phosphorene (black phosphorus with a single atomic layer thickness) is a natural p-type semiconductor. ${ }^{[11,12]}$ When the valence band electrons jump vertically to the conduction band, the electron wave vector does not change accordingly. Therefore, it has a direct bandgap, and the bandgap can be controlled by the number of layers in the range of $\approx 0.3 \mathrm{eV}$ (about 30 layers) to $\approx 1.5 \mathrm{eV}$ (single layer). ${ }^{[11-13]}$ Moreover, it shows obvious anisotropy, and the elastic modulus in the $x$-direction and the effective mass of the crystal electrons are small, which makes the black phosphorus with high electron mobility. Furthermore, the electron mobility of the single layer black phosphorus can reach $10^{4} \mathrm{~cm}^{2} \mathrm{~V}^{-1} \mathrm{~s}^{-1} \cdot{ }^{[14]}$

In general, BP is widely used in the field of photocatalysis because of its adjustable bandgap. Previously, Yu and co-workers ${ }^{[15]}$ showed a black-red phosphorus heterostructure as visible-light-driven photocatalysis synthesized by a simple ball-milling method. Majima and co-workers ${ }^{[16]}$ demonstrated that the $\mathrm{BP} /$ graphitic carbon nitride was used as a photocatalyst for $\mathrm{H}_{2}$ evolution invisible to near-infrared region. The photoelectric effect of few-layers BP nanosheets has been fully revealed. On the other hand, electrocatalytic performances of pure few-layers BP nanosheets for OER were reported to testify further implementation. ${ }^{[17]}$

Except for spacious surface areas and admirable electron conductivity, luxuriant edge sites play a vital role in the catalytic process. ${ }^{[9,18]}$ As is known, transition metal nitrides may befittingly absorb between the surface of nitrides and the protons due to the characteristic electronic structure. At the same time, plentiful active sites render transition metal nitrides emerge as one kind of highly efficient electrocatalyst for hydrogen generation. ${ }^{[19]}$ Vaidhyanathan and co-workers ${ }^{[20]}$ established benzimidazole covalent organic framework (COF) supported $\mathrm{Ni}_{3} \mathrm{~N}$ as the catalyst for OER oxidizes alkaline water with a topping low overpotential of $230 \mathrm{mV} @ 10 \mathrm{~mA} \mathrm{~cm}{ }^{-2}$. Chen and co-workers ${ }^{[21]}$ designed cobalt nickel nitride nanowires which were self-supported for overall electrochemical water splitting.
Based on the above discussion, we put forward a rational way to build the graphene-black phosphorus hybrids for supporting $\mathrm{Ni}_{3} \mathrm{~N}$ to enhance the OER activity. Through simply ball-milling process, the graphene activated through $\mathrm{KOH}(\mathrm{AG})$ is rationally combined with $\mathrm{BP}$ and $\mathrm{Ni}_{3} \mathrm{~N}$. The results demonstrated that the $\mathrm{Ni}_{3} \mathrm{~N} / \mathrm{BP}-\mathrm{AG}$ demonstrates not only high OER activity with low overpotential but also benign stability in alkaline condition. The $\mathrm{Ni}_{3} \mathrm{~N} / \mathrm{BP}$-AG shows better advantages than the commercial Ru-based and Ir-based OER catalysts. Hence, we have reason to believe that the $\mathrm{Ni}_{3} \mathrm{~N} / \mathrm{BP}-\mathrm{AG}$ will have great potential in electrocatalyst for OER.

\section{Results and Discussion}

\subsection{Characterization of $\mathrm{Ni}_{3} \mathrm{~N} / \mathrm{BP}-\mathrm{AG}$ Catalysts}

In this paper, the activated graphene (AG) was obtained by commercial pristine graphene nanosheets which were originated from mechanical exfoliation of graphite activated by $6 \mathrm{M}$ $\mathrm{KOH}_{.}{ }^{[22]} \mathrm{BP}$ was prepared by ball-milling red phosphorus (RP). Moreover, $\mathrm{Ni}_{3} \mathrm{~N}$ particles were gained via the reported method. First, $\mathrm{NiCl}_{2} \cdot 6 \mathrm{H}_{2} \mathrm{O}$ reacts with $\mathrm{NH}_{4} \mathrm{~F}$ and urea in a hydrothermal reaction to form precursor. Then the green precursor was heated at $380{ }^{\circ} \mathrm{C}$ for $2 \mathrm{~h}$ under the $\mathrm{NH}_{3}$ atmosphere to produce the $\mathrm{Ni}_{3} \mathrm{~N}$ particles. ${ }^{[23]}$ As illustrated in Scheme 1, the preparation of AG/BP hybrids was achieved through ball milling of $\mathrm{AG}$ and $\mathrm{BP}$ with the high pressure and temperature under engorged argon protection. After that, the as-prepared $\mathrm{Ni}_{3} \mathrm{~N}$ was transferred into the jar for further ball milling. Finally, the catalyst was indexed as $\mathrm{Ni}_{3} \mathrm{~N} / \mathrm{BP}-\mathrm{AG}-1$ according to the mass ratio of $\mathrm{Ni}_{3} \mathrm{~N}$ : $\mathrm{BP}: \mathrm{AG}=1: 1: 1$.

Figure 1a shows X-ray diffraction (XRD) patterns of the $\mathrm{BP}$, $\mathrm{AG}, \mathrm{Ni}_{3} \mathrm{~N}, \mathrm{BP}-\mathrm{AG}$, and the $\mathrm{Ni}_{3} \mathrm{~N} / \mathrm{BP}-\mathrm{AG}-1$ hybrids, respectively. Following the standard XRD pattern of orthorhombic BP (Joint Committee on Powder Diffraction Standards (JCPDS) No. 73-1358), BP gained by ball-milling pattern owns the emblematic peaks at $2 \theta=15^{\circ}, 33.5^{\circ}$, and $55.6^{\circ},{ }^{[15]}$ which suggests the existence of black phosphorus with small crystal size. The

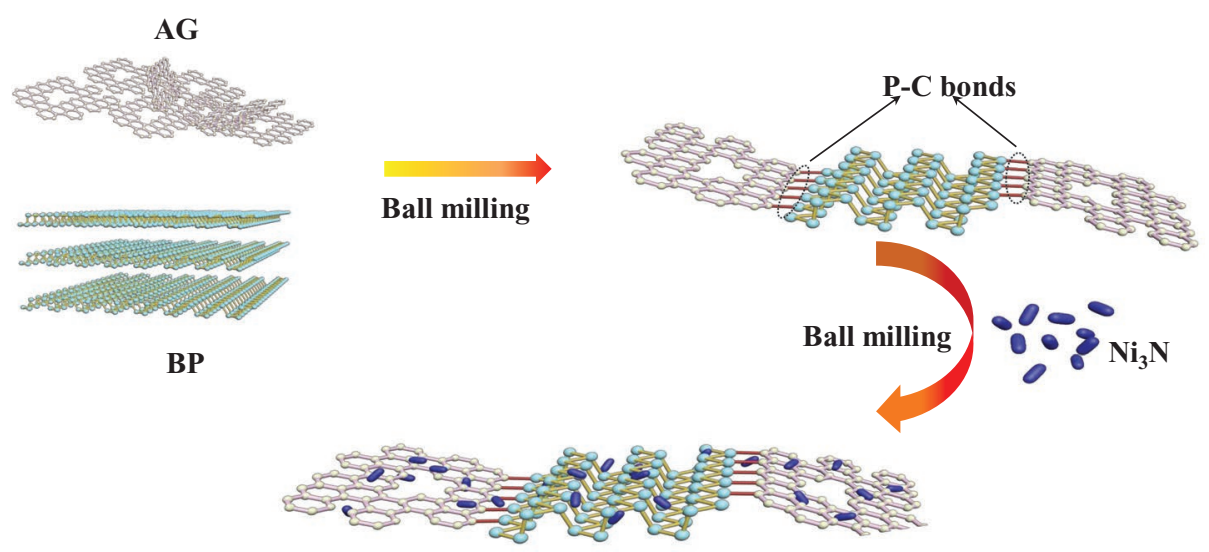

$\mathrm{Ni}_{3}$ N/BP-AG Catalysts

Scheme 1. Schematic illustration of the fabrication of the $\mathrm{Ni}_{3} \mathrm{~N} / \mathrm{BP}-\mathrm{AG}$ hybrids. 


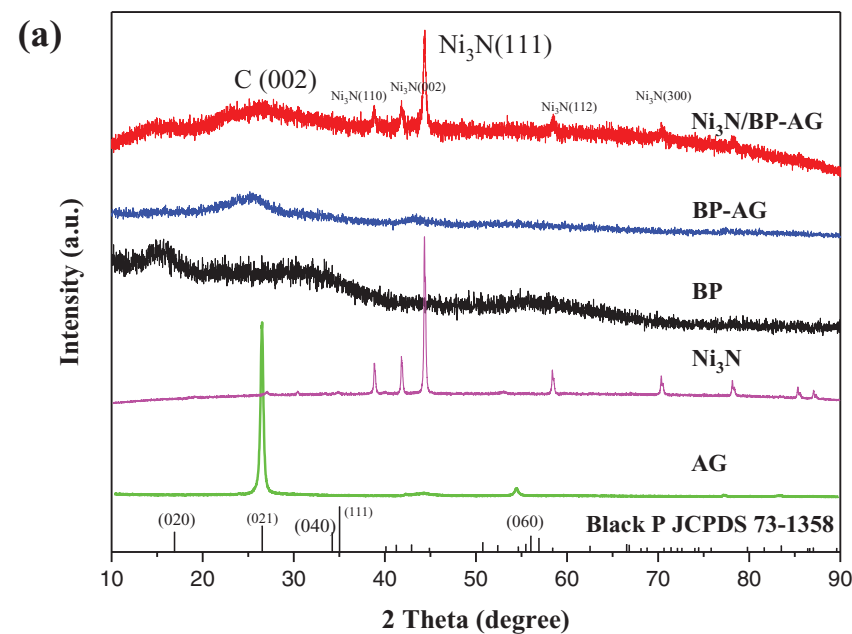

Figure 1. a) XRD patterns of $B P, A G, N_{3} N, B P-A G$, and $N i_{3} N / B P-A G$ and b) Raman spectra of $B P-A G$ (Inset of (b): Raman spectra of $B P$ ).

diffraction peak at $25.6^{\circ}$ in $\mathrm{AG}$ is consistent with the plane of graphite (002). ${ }^{[22]}$ All the diffraction peaks support that the crystalline structure of hexagonal $\mathrm{Ni}_{3} \mathrm{~N}$ with purity phases indexes well to the hybrids (according to the JCPDS 10-0280, $a=b=4.621 \AA ; c=4.304 \AA$ ) while ball milling with the BP and AG. Moreover, the diffraction peaks of the $\mathrm{Ni}_{3} \mathrm{~N}$ (111), (002), (110), and (112) planes in the patterns of the $\mathrm{Ni}_{3} \mathrm{~N} / \mathrm{BP}-\mathrm{AG}-1$ hybrids are weaker than those of the pure $\mathrm{Ni}_{3} \mathrm{~N}$, which may owe to the doping of $\mathrm{P}$ species in the crystal lattice of partial $\mathrm{Ni}_{3} \mathrm{~N}$ particles. This result may be same as the circumstance of the weak $\mathrm{C}$ peak at $25.6^{\circ}$ in BP-AG. In addition, the diagnostic peaks of BP cannot be presented distinctly in the XRD pattern of $\mathrm{Ni}_{3} \mathrm{~N} / \mathrm{BP}$-AG hybrids, which could be attributed to the reaction process accompanied with the oxidation of few-layer $\mathrm{BP}$ and destruction caused by the generation of $\mathrm{P}-\mathrm{C}$ bonding and formation of $\mathrm{P}_{x} \mathrm{O}_{y}$ during the individual reaction. ${ }^{[24,25]}$ And the basement would be more stabilized because of the $\mathrm{P}-\mathrm{C}$ bonds. ${ }^{[22]}$ From the inserted Raman spectrum of Figure 1b, Raman peak located at $362 \mathrm{~cm}^{-1}$ can be assigned to the $\mathrm{A} 1 \mathrm{~g}$ mode, while peaks at 440 and $467 \mathrm{~cm}^{-1}$ are conforming to the in-plane $\mathrm{B}_{2 \mathrm{~g}}$ and $\mathrm{A} 2 \mathrm{~g}$ modes of commercial BP bulk, respectively. ${ }^{[2]} \mathrm{By}$ contrast, the peaks of as-prepared BP nanosheets by mechanical exfoliation are transferred to lower wavenumber for about 13,9 , and $3 \mathrm{~cm}^{-1}$, which may be ascribed to the degeneration of BP nanosheets with the decrease of thickness in consistent with the previous analysis. ${ }^{[17]}$ Figure $1 \mathrm{~b}$ also plots a typical Raman spectrum of the BP-AG. Except for the D peak, the significant $G$ peak of graphene appears distinctly. In addition, this consequence hints the component combined with $\mathrm{BP}$ are few layers. ${ }^{[27]}$ Extra, the $I_{\mathrm{D}} / I_{\mathrm{G}}$ with a spectacular intensity ratio $\approx 2.1$ is attributed to the edges of nanosheets and the appearance of a large number of structural defects within the chips, which is in favor of the exposure of active sites. ${ }^{[28]}$ It is fairly well known that along with the ball-milling process, the defects of BP nanosheets are amplified. And the lifted edges are produced correspondingly.

The AG nanosheets can be seen clearly in Figure 2a. Under the electron irradiation, the graphene is nearly transparent. From the inserted image of Figure 2a, the thin AG nanoflakes with about six to eight layers can be seen clearly. According

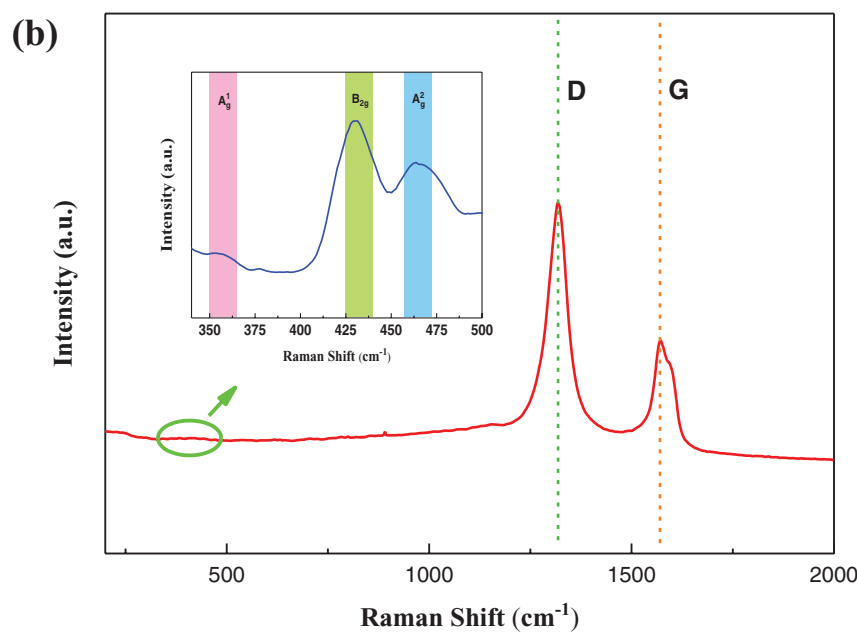

to $\mathrm{Yu}$ and co-workers, ${ }^{[15]}$ the $\mathrm{BP}$ which can be gained via easy ball-milling red phosphorus is shown in Figure 2b. Figure 2c is the amplifying image of Figure $2 \mathrm{~b}$. It shows the representative transmission electron microscopy (TEM) image of laminar BP nanosheets. By attention to this inset, the edge of BP confirms that the nanosheets are about six layers and the performance of less layers BP is better than bulk BP for OER. ${ }^{[9]}$ As shown in Figure 2d, the characteristic lattice distance of $0.26 \mathrm{~nm}$ is in keeping with the (040) faces of BP. The crosssectional atomic force microscopy (AFM) images as shown in Figure S1 in the Supporting Information demonstrate that the standalone BP is about $3.4 \mathrm{~nm}$, which echoes the result of the former. Besides, the results further indicate that the integrated layer structure of BP nanosheets has been generated and retained during the ball-milling process. In other words, the lamellar BP nanosheets with characteristic structure have been gained. From the TEM image of Figure 2e,f, there is a distinct boundary of AG and BP from the AG-BP heterostructure. One side, the curved lattice fringes with as the characteristic of graphene can be seen obviously. The lattice distance of $0.34 \mathrm{~nm}$ is putting down to the C (002) flat interplanar spacing of AG. And the other side, the conterminous BP with (040) faces can be found. From the boundary between AG and $\mathrm{BP}$, the AG-BP heterostructure is positively built. Therefore, compared to single substance, the active sites and charge transfer in AG-BP for direct activation of molecular oxygen and substrate are improved because of the heterojunction effect. ${ }^{[8,29]}$ Furthermore, the situation of $\mathrm{Ni}_{3} \mathrm{~N} / \mathrm{BP}$-AG-1 hybrids can be probed from Figure 3a. Compared with the previous $\mathrm{AG}$, the $\mathrm{Ni}_{3} \mathrm{~N} / \mathrm{BP}-\mathrm{AG}$ nanosheets became opaque due to the loading of $\mathrm{BP}$ and $\mathrm{Ni}_{3} \mathrm{~N}$. In the high-resolution TEM images (Figure 3b,c), the symbolization of $\mathrm{Ni}_{3} \mathrm{~N}$ particles were represented by the lattice fringes with the interplanar distance of $0.21 \mathrm{~nm}$. And the distance is corresponding well to (111) planes of $\mathrm{Ni}_{3} \mathrm{~N}$. This result shows that $\mathrm{Ni}_{3} \mathrm{~N}$ particles are present on the BP-AG heterojunction substrate. As witnessed from Figure 3d and Figure S2 in the Supporting Information, energy dispersive spectroscopy (EDS) analysis indicated that $\mathrm{BP}$ and AG combined well with the $\mathrm{Ni}_{3} \mathrm{~N}$ particles which were distributed uniformly. 

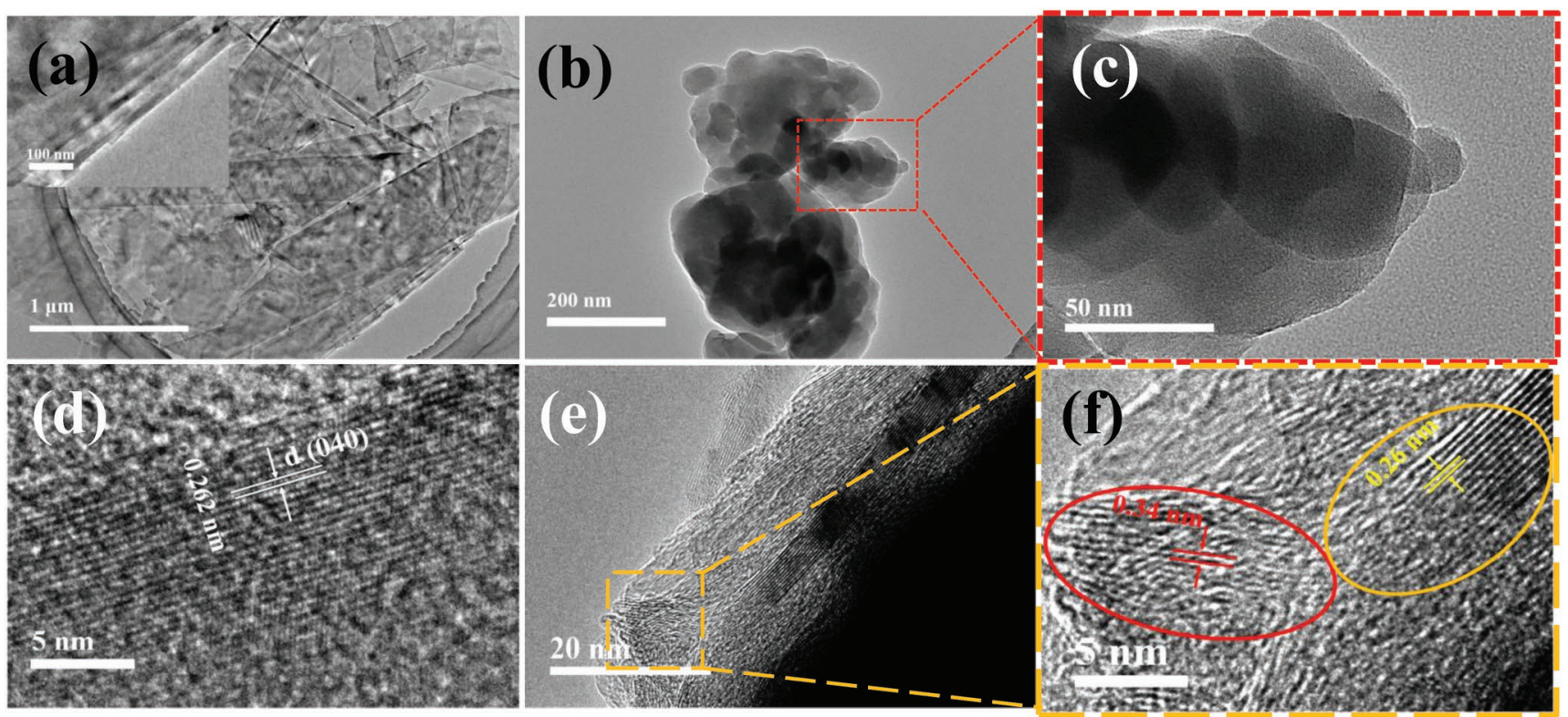

Figure 2. a) TEM image of $A G, b, c)$ TEM image of $B P, d$ ) high-resolution transmission electron microscopy (HRTEM) image of BP, and e,f) HRTEM image of BP-AG.

The electronic structure and surface information of $\mathrm{Ni}_{3} \mathrm{~N} /$ BP-AG-1 hybrids were explored by X-ray photoelectron spectroscopy (XPS). The characteristic peaks of C 1s, N 1s, P 2p, Ni 2p, and $\mathrm{O} 1 \mathrm{~s}$ are shown in Figure 4a, respectively. For checking the peak shifts, the standard C 1s peak at $284.6 \mathrm{eV}$ is selected as a reference and the $\mathrm{O}$ signal is from the surface oxidation. For $\mathrm{Ni}_{3} \mathrm{~N} / \mathrm{BP}-\mathrm{AG}-1$ hybrids sample (Figure $4 \mathrm{~b}$ ), the appeared peaks located at $\approx 856.9$ and $\approx 874.8 \mathrm{eV}$ are attributed to the $\mathrm{Ni}$
$2 p_{3 / 2}$ and Ni $2 p_{1 / 2}$, respectively. The quite strong respond is corresponding to the $\mathrm{Ni}^{2+}$. This result confirms the existence of Ni-P bonds. ${ }^{\left[{ }^{[0]}\right.}$ Meanwhile, the peak located at $853.2 \mathrm{eV}$ can be assigned to $\mathrm{Ni}^{+}$in $\mathrm{Ni}_{3} \mathrm{~N}$. Identically, the $\mathrm{N}$ atoms were successfully boned with the $\mathrm{Ni}$ atoms according to the main characteristic peak centered at $\approx 398 \mathrm{eV}$ which could be observed in the high-resolution N 1s XPS spectrum (Figure 4e). On the other hand, the sectional $\mathrm{Ni}^{+}$and $\mathrm{Ni}^{2+}$ could be oxidized into
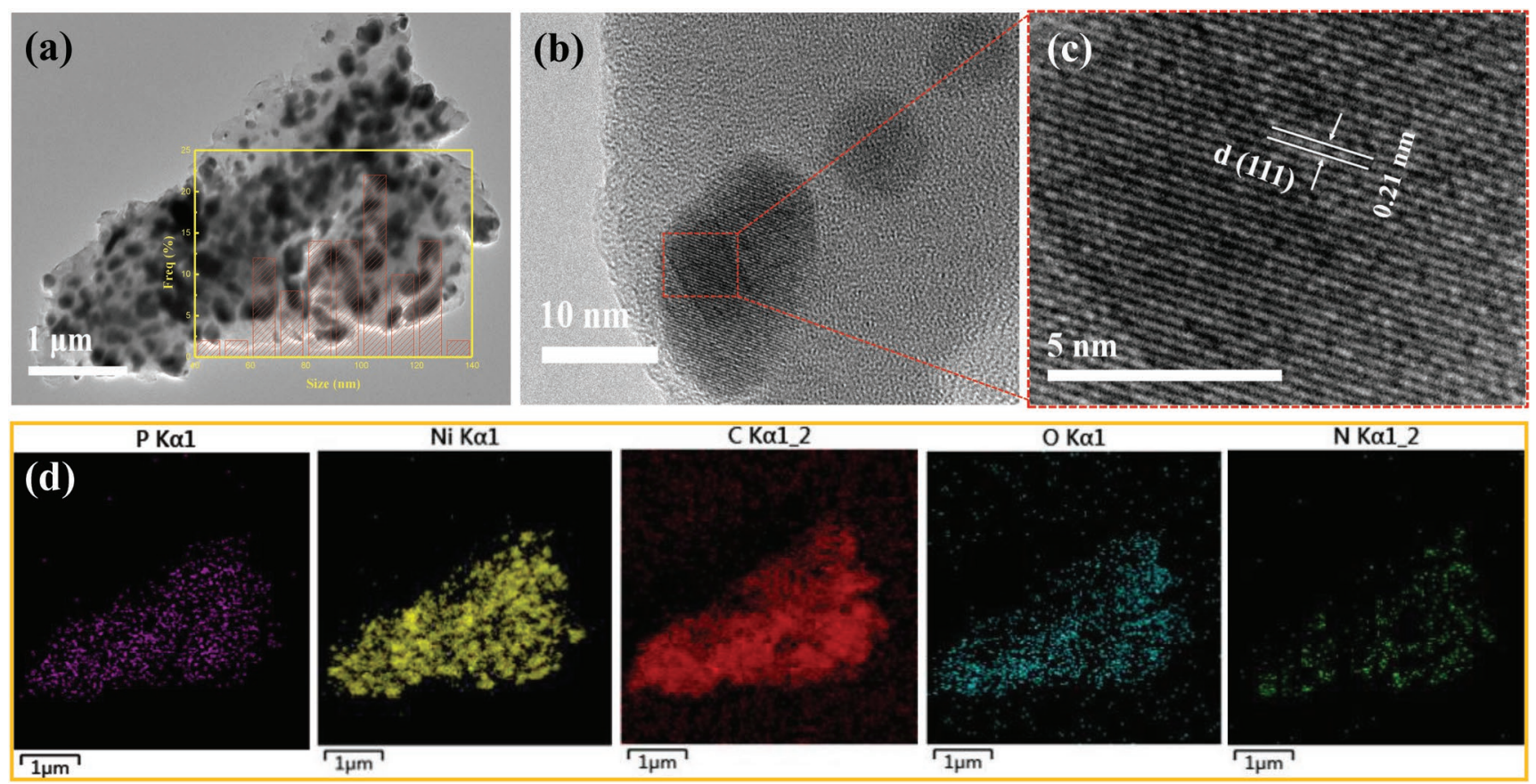

Figure 3. a) TEM image of $\left.\mathrm{Ni}_{3} \mathrm{~N} / \mathrm{BP}-\mathrm{AG}-1, \mathrm{~b}, \mathrm{c}\right)$ HRTEM image of $\mathrm{Ni} \mathrm{i}_{3} \mathrm{~N} / \mathrm{BP}-\mathrm{AG}-1$, and d) EDS mapping images for $\mathrm{P}, \mathrm{Ni}, \mathrm{C}, \mathrm{N}$, and $\mathrm{O}$ elements in $\mathrm{Ni}_{3} \mathrm{~N} / \mathrm{BP}-\mathrm{AG}-1$. (Inset of (a): Size distribution of $\mathrm{Ni}_{3} \mathrm{~N}$ particles on the surface of the BP-AG support.) 

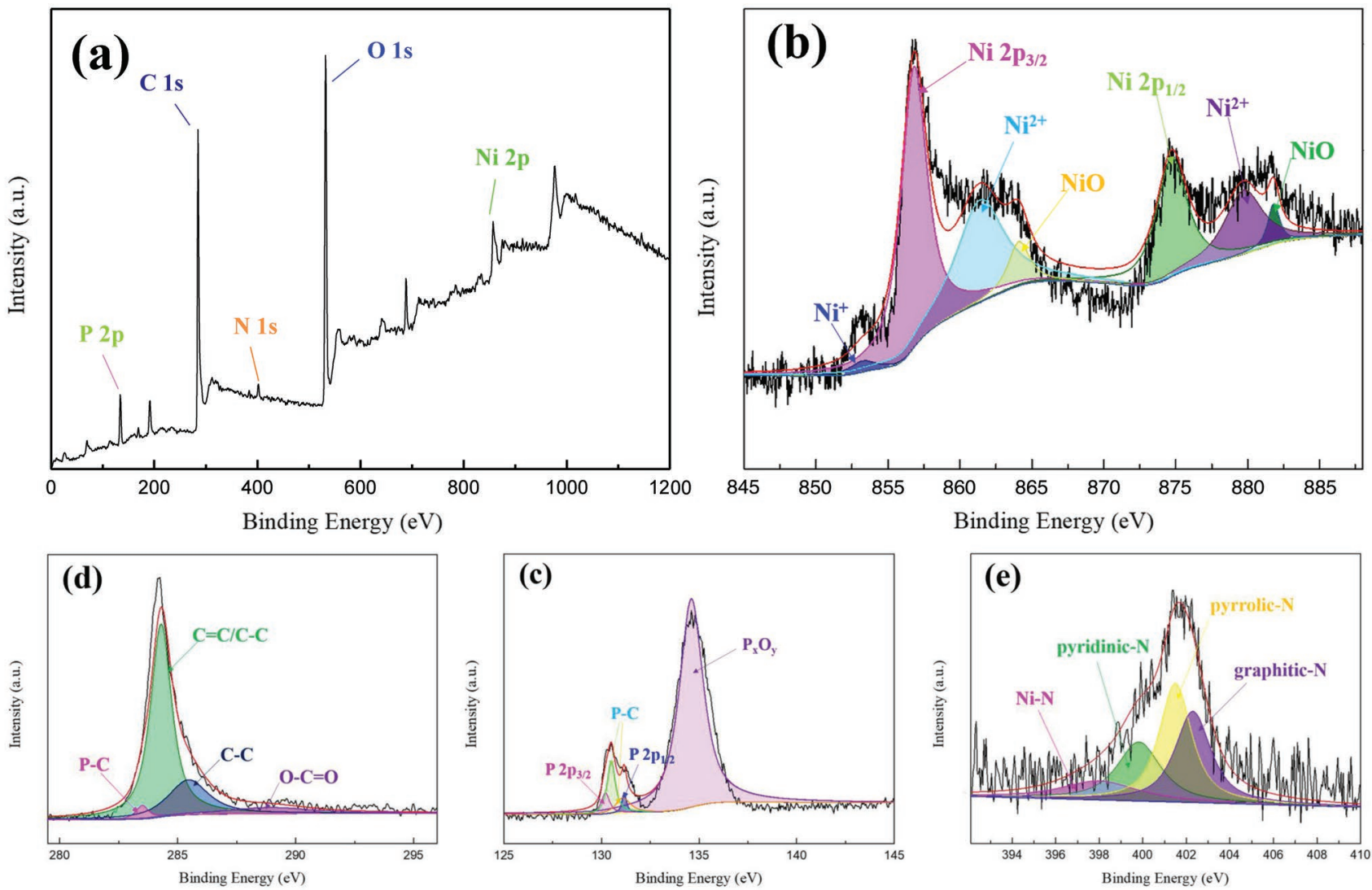

Figure 4. a) XPS survey of $\mathrm{Ni}_{3} \mathrm{~N} / \mathrm{BP}-\mathrm{AG}-1$ and high-resolution region of b-e) $\mathrm{Ni} 2 \mathrm{p}, \mathrm{P} 2 \mathrm{p}, \mathrm{C}$ 1s, and $\mathrm{N} 1 \mathrm{~s}$ in the Ni ${ }_{3} \mathrm{~N} / \mathrm{BP}-\mathrm{AG}-1$.

$\mathrm{NiO}$ and $\mathrm{NiOOH}$, respectively. The $\mathrm{NiOOH}$ can be further oxidized into NiOOO* as the active sites. ${ }^{[19,23]}$ It is assumed that OER is a four-step electron transfer process involving the formation of intermediates $* \mathrm{OH}, * \mathrm{O}, * \mathrm{OOH}$, and $\mathrm{O}_{2},{ }^{[23,32]}$ and the surface $\mathrm{Ni}$ sites are considered to be the adsorption sites for binding oxygen intermediates. ${ }^{[31]}$ As we know, the largest reaction barrier is determined by the maximum ratelimiting energy barrier. And this barrier is from the formation of $* \mathrm{OOH}$ in the reaction. Interestingly, even though the step before the formation of $* \mathrm{OOH}$ is spontaneous for $\mathrm{Ni}_{3} \mathrm{~N}$, the large energy barrier value in the formation of $* \mathrm{OOH}$ also limits the progress of the reaction. However, in the catalyst, both of $\mathrm{NiO}$ and $\mathrm{Ni}_{3} \mathrm{~N}$ are present. Therefore, the result may imply the existence of coupled nanointerface between $\mathrm{NiO}$ and $\mathrm{Ni}_{3} \mathrm{~N}$ with optimized surface electronic structure during the reaction which can reduce the energy barrier in the ratelimiting step. ${ }^{[31]}$

Furthermore, Figure 4c displays the high-resolution P 2p XPS spectra, and the peaks stand for the P $2 \mathrm{p}_{3 / 2}$ and $\mathrm{P} 2 \mathrm{p}_{1 / 2}$ are positioned on 130.02 and $130.81 \mathrm{eV}$, respectively, which can confirm the presence of phosphorus-phosphorus bonds derived from BP. ${ }^{[22,24]}$ The reflection focus on $\approx 134.4 \mathrm{eV}$ uncovers the formation of the most prevalent phosphorous oxides $\left(\mathrm{P}_{x} \mathrm{O}_{\gamma}\right)$. As shown in Figure 4b,c and Figure S3 in the Supporting Information, it is noteworthy that the peaks reveal shifts to higher binding energy (BE) by $0.9 \mathrm{eV}$ for $\mathrm{P}-\mathrm{O}$ and $0.4 \mathrm{eV}$ for P 2p, lower BE by $0.6 \mathrm{eV}$ for $\mathrm{Ni} 2 \mathrm{p}$ (133.5 eV for $\mathrm{P}-\mathrm{O}, 129.6 \mathrm{eV}$ for P $2 \mathrm{p}_{3 / 2}$. $130.4 \mathrm{eV}$ for $\mathrm{P} 2 \mathrm{p}_{1 / 2}, 857.5 \mathrm{eV}$ for $\mathrm{Ni}$
$2 \mathrm{p}_{3 / 2}$, and $875.4 \mathrm{eV}$ for $\left.\mathrm{Ni} 2 \mathrm{p}_{1 / 2}{ }^{[18,19,22,26]}\right)$ in $\mathrm{Ni}_{3} \mathrm{~N} / \mathrm{BP}-\mathrm{AG}-1$. The augment of BE indicates the weak electron density screening effect due to the decrease of the electron density. Oppositely, the decrease illustrates the enhancement of electron density. ${ }^{[32]}$ On this side, a point can be inferred. First, the electrons move from $\mathrm{P}$ to the interface of $\mathrm{Ni}_{3} \mathrm{~N} /$ heterostructure, and then, from $\mathrm{Ni}_{3} \mathrm{~N} /$ heterostructure to $\mathrm{Ni}$ sites. This transformation leads to the higher shifts of P $2 \mathrm{p}$ and lower BE shifts of Ni 2p. ${ }^{[26]}$ As for the generation of robust $\mathrm{P}-\mathrm{C}$ bonds in the course of ball milling, the peaks of 130.46 and $131.68 \mathrm{eV}^{[22]}$ are ascribed to the representative reflection of $\mathrm{P} 2 \mathrm{p}_{1 / 2}$ and $\mathrm{P} 2 \mathrm{p}_{3 / 2}$ from the generated $\mathrm{P}-\mathrm{C}$ bond. Besides that, the evidence of $\approx 283.5 \mathrm{eV}^{[22]}$ can be found from Figure $4 \mathrm{~d}$. Therefore, the structural stability of the AG-BP substrate can be improved due to the diverse interfaces between BP and AG. At the same time, the jarless construction promotes the stability and contact between the exposed reaction sites and electrolyte on the OER process in an alkaline condition.

In addition, the peaks of $\mathrm{C} 1 \mathrm{~s}$ XPS in Figure $4 \mathrm{~d}$ conform to the bonds of $\mathrm{C}-\mathrm{C} / \mathrm{C}=\mathrm{C}, \mathrm{C}-\mathrm{C}$. And the $\mathrm{O}-\mathrm{C}=\mathrm{O}$ bond is found extra because of the oxidation of heterostructure surface. This bond that embraces oxygen atoms can be accessorial reaction sites for the evolution of $\mathrm{O}_{2} \cdot{ }^{[19]}$ As illustrated in Figure 4e, the emblematic peaks located at 398.8, 400.1, and $401.2 \mathrm{eV}$ can be divided into the pyridinic- $\mathrm{N}$, pyrrolic- $\mathrm{N}$, and graphitic- $\mathrm{N}$, respectively. In this respect, partial $\mathrm{N}$ atoms are doped into the graphene during the reaction. ${ }^{[33]}$ At the same time, the $\mathrm{N}$ atoms may become a bridge connecting the $\mathrm{Ni}_{3} \mathrm{~N}$ and the 
heterojunction substrate. This creates complete channels for electron transport in the OER process on the $\mathrm{Ni}_{3} \mathrm{~N} / \mathrm{BP}-\mathrm{AG}-1$ body.

\subsection{Electrocatalytic Performances}

The electrocatalytic OER activities of the obtained samples have been verified in an alkaline condition. At first, a three-electrode configuration had been used to examine the catalytic activities of the compounds for OER in $\mathrm{O}_{2}$-saturated $1.0 \mathrm{M} \mathrm{KOH}$ with the catalyst loading of $254.78 \mu \mathrm{g} \mathrm{cm} \mathrm{cm}^{-2}$. In order to initially explore the optimal ratio of catalysts, there are several kinds of mass ratio had been selected. Here, three types of catalysts are revealed. Those are $\mathrm{Ni}_{3} \mathrm{~N}: \mathrm{BP}: \mathrm{AG}=2: 1: 1\left(\mathrm{Ni}{ }_{3} \mathrm{~N} / \mathrm{BP}-\mathrm{AG}-2\right)$, 1:1:1 $\left(\mathrm{Ni}_{3} \mathrm{~N} / \mathrm{BP}-\mathrm{AG}-1\right)$, and 0.5:1:1 $\left(\mathrm{Ni}_{3} \mathrm{~N} / \mathrm{BP}-\mathrm{AG}-0.5\right)$, respectively. And all potentials in this paper are based on reversible hydrogen electrode (RHE).

The IR-corrected linear scan voltammetry (LSV) polarization curves toward OER for catalysts have been displayed in Figure $5 \mathrm{a}$, the prepared $\mathrm{Ni}_{3} \mathrm{~N} / \mathrm{BP}-\mathrm{AG}$ catalysts with different
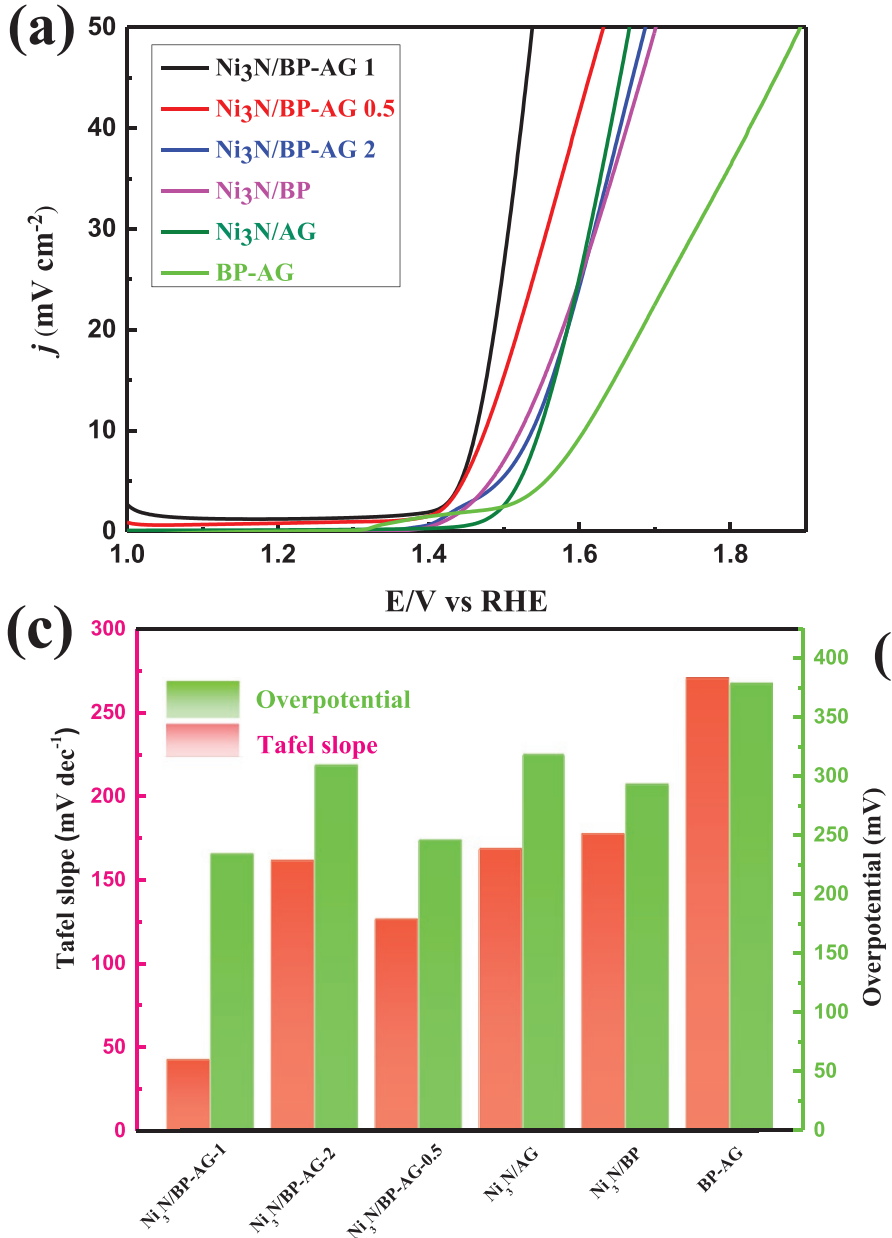

Figure 5. OER performance. a) IR compensated polarization curves of the $N i_{3} N / B P-A G-2, N i_{3} N / B P-A G-1, N i_{3} N / B P-A G-0.5, N i_{3} N / B P, N i_{3} N / A G$, and BP-AG, scan rate: $5 \mathrm{mV} \mathrm{s}^{-1}$. b) Tafel slopes, c) the summarized overpotentials and Tafel plots at the $10 \mathrm{~mA} \mathrm{~cm}^{-2}$, and d) plots of the double-layer capacitances.
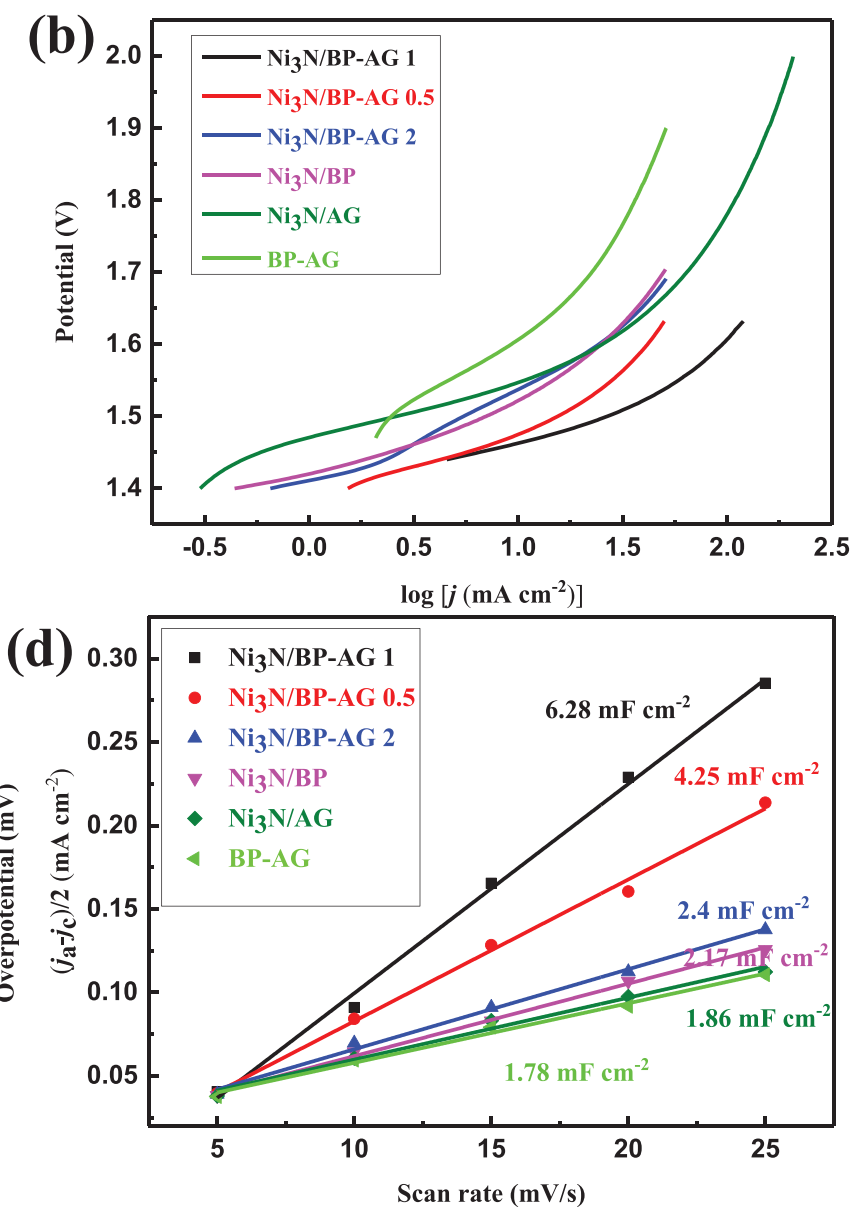

proportions of formula, $\mathrm{Ni}_{3} \mathrm{~N} / \mathrm{BP}, \mathrm{Ni}_{3} \mathrm{~N} / \mathrm{AG}$, and $\mathrm{BP}-\mathrm{AG}$ hybrids were investigated together for comparison. The $\mathrm{Ni}_{3} \mathrm{~N} / \mathrm{BP}-\mathrm{AG}$ with the frequently used mass ratio of $1: 1: 1$ $\left(\mathrm{Ni}{ }_{3} \mathrm{~N} / \mathrm{BP}-\mathrm{AG}-1\right)$ only demands an overpotential of $\approx 233 \mathrm{mV}$ to reach $10 \mathrm{~mA} \mathrm{~cm}^{-2}$. While the other options require higher overpotentials for the current density of $10 \mathrm{~mA} \mathrm{~cm}{ }^{-2}(308 \mathrm{mV}$ for $\mathrm{Ni}_{3} \mathrm{~N} / \mathrm{BP}-\mathrm{AG}-2,245 \mathrm{mV}$ for $\mathrm{Ni}_{3} \mathrm{~N} / \mathrm{BP}-\mathrm{AG}-0.5,317 \mathrm{mV}$ for $\mathrm{Ni}_{3} \mathrm{~N} /$ AG, $292 \mathrm{mV}$ for $\mathrm{Ni}_{3} \mathrm{~N} / \mathrm{BP}$, and $377 \mathrm{mV}$ for BP-AG, severally). The overpotential for $\mathrm{Ni}_{3} \mathrm{~N} / \mathrm{BP}-\mathrm{AG}-1$ was optimized and even much better than the commercial $\mathrm{RuO}_{2}$ catalyst which needs an overpotential of more than $300 \mathrm{mV}$ at the same condition. And the supererogatory expense of energy undisputed accompanied by the large overpotential. The lower overpotential is excellent among other recently reported active OER catalysts by contrast (Figure S4, Supporting Information ${ }^{[19,26,34-38]}$ ).

As a pivotal kinetic parameter, Tafel slope values are frequently used to incarnate the OER pathway and the rate-limiting step of the electrochemical behavior. ${ }^{[39]}$ Therefore, a four-electron transfer process can be discovered while the mechanism of OER in alkaline solution is analyzed. Same as before, the smallest Tafel slope of $42 \mathrm{mV} \mathrm{dec}{ }^{-1}$ belongs to $\mathrm{Ni}_{3} \mathrm{~N} / \mathrm{BP}-\mathrm{AG}-1$ 
within all the options indicating a changed rate-determining step (Figure $5 \mathrm{~b}$ ). While the corresponding Tafel slopes of $\mathrm{Ni}_{3} \mathrm{~N} /$ BP-AG-2, Ni ${ }_{3}$ N/BP-AG-0.5, $\mathrm{Ni}_{3} \mathrm{~N} / \mathrm{BP}, \mathrm{Ni}_{3} \mathrm{~N} / \mathrm{AG}$, and BP-AG are

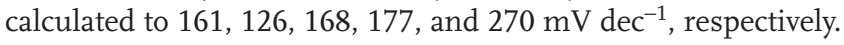
Figure $5 \mathrm{c}$ summarizes the essential property of electrocatalysts. It is pretty evident that the $\mathrm{Ni}_{3} \mathrm{~N} / \mathrm{BP}-\mathrm{AG}-1$ is the best in both overpotential and Tafel slope. The performance of other catalysts in this series is shown in Figure S5 in the Supporting Information.

In contrast, the source of benign value might give credit to the surface and interface structure of compound, which keep the building steady. And the defects of nanosheets for absorbing $* \mathrm{OH}$ are operated successfully. Surface hydrogen/oxide complexes that are readily formed during electrolysis have been formed to be synergistic catalytically active sites for the reported nitride or phosphide OER catalysts. ${ }^{[31]}$ Moreover, as previously speculated, the acceleration of the kinetics is also likely to be inseparable from the complete electron transfer channel of the catalyst. And the special interface between $\mathrm{NiO}$ and $\mathrm{Ni}_{3} \mathrm{~N}$ is conducive to form active sites with spectacular efficiency. ${ }^{[31]}$ On the other hand, it is recognized that the existence of $\mathrm{Ni}^{2+}$ which could be further oxidized to NiOOO* plays an important role in the catalytic process. ${ }^{[19,23]}$

$\mathrm{Ni}^{2+}+3 \mathrm{OH}^{-} \leftrightarrow \mathrm{NiOOH}+\mathrm{H}_{2} \mathrm{O}+\mathrm{e}^{-}$

$\mathrm{NiOOH}+\mathrm{OH}^{-} \leftrightarrow \mathrm{NiO}(\mathrm{OH})_{2}+\mathrm{e}^{-}$

$\mathrm{NiO}(\mathrm{OH})_{2}+2 \mathrm{OH}^{-} \leftrightarrow \mathrm{NiOO}_{2}+2 \mathrm{H}_{2} \mathrm{O}+2 \mathrm{e}^{-}$

$\mathrm{NiOO}_{2}+\mathrm{OH}^{-} \rightarrow \mathrm{NiOOH}+\mathrm{O}_{2}+\mathrm{e}^{-}$

OER: $4 \mathrm{OH}^{-} \rightarrow \mathrm{O}_{2}+2 \mathrm{H}_{2} \mathrm{O}+4 \mathrm{e}^{-}$

To further understand the mechanism of OER in the $\mathrm{Ni}^{2+}$ sites, four basic steps which had been explored by previous researchers can be described as shown above. ${ }^{[23]}$ In the

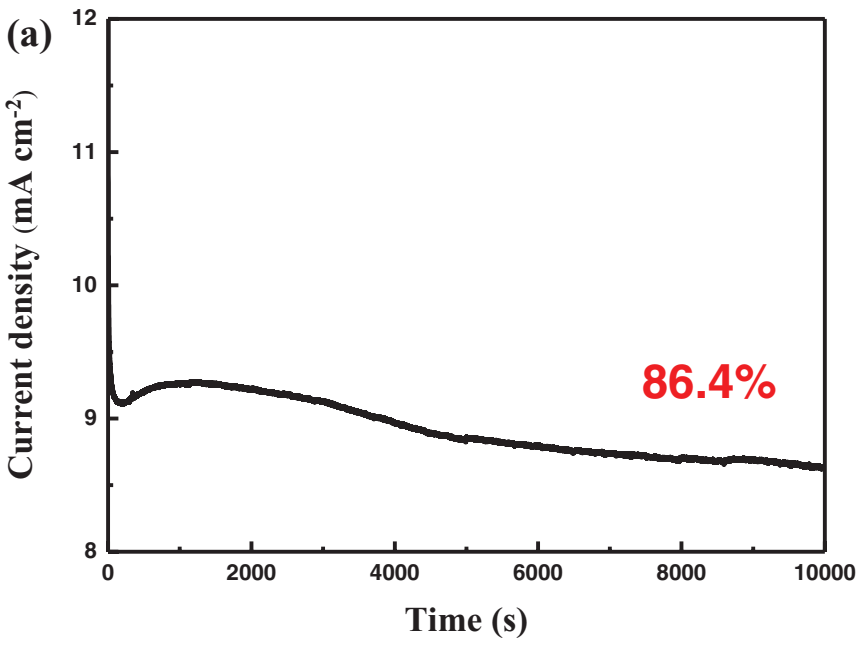

beginning, the $\mathrm{Ni}^{2+}$ combines with the ${ }^{*} \mathrm{OH}$ in the electrolyte to form the $\mathrm{NiOOH}$. Then, the $\mathrm{NiOOH}$ further reacts with the $* \mathrm{OH}$. As a result, the $\mathrm{NiOOO} *$ integrates with the $* \mathrm{OH}$ in the third step. In this step, the $\mathrm{NiOO}_{2}$ and $\mathrm{H}_{2} \mathrm{O}$ will be fabricated simutanuously. Finally, the $\mathrm{NiOO}_{2}$ acts with the $* \mathrm{OH}$ again to finish the process of four-step electron transfer. The first three steps identify the rate of all OER. Particularly, the simultaneous regeneration of $\mathrm{NiOOH}$ is accompanied by the formation of oxygen. That means partial energy barrier of reaction may be reduced in the next courses. Thus, the excellent property of $\mathrm{Ni}_{3} \mathrm{~N} / \mathrm{BP}-\mathrm{AG}-1$ for OER may be explained.

The effective electrochemical active surface area of catalysts was investigated in Figure $5 \mathrm{~d}$ for interpretation of the improved OER performance pertain to $\mathrm{Ni}_{3} \mathrm{~N} / \mathrm{BP}-\mathrm{AG}-1$ by estimating the double-layer capacitance $\left(C_{\mathrm{dl}}\right)$ on the basis of the cyclic voltammetry $(\mathrm{CV})$ results at different scan rates. As can be seen from the illustration, the capacitance from $\mathrm{Ni}_{3} \mathrm{~N} / \mathrm{BP}$-AG-1 electrode reaches up to $6.28 \mathrm{mF} \mathrm{cm} \mathrm{cm}^{-2}$. This value greatly exceeds the second value of $4.25 \mathrm{mF} \mathrm{cm}{ }^{-2}\left(\mathrm{Ni}_{3} \mathrm{~N} / \mathrm{BP}-\mathrm{AG}-0.5\right)$, which suggests that $\mathrm{Ni}_{3} \mathrm{~N} / \mathrm{BP}-\mathrm{AG}-1$ shows the most effective active sites. Further, electrochemical impedance spectroscopies of catalysts are investigated (Figure S6a, Supporting Information). The classic Nyquist plots show the diameter of the semicircles diminution, manifesting that $\mathrm{Ni}_{3} \mathrm{~N} / \mathrm{BP}-\mathrm{AG}-1$ has the fastest electron transfer. ${ }^{[32]}$ Therefore, it is obvious that the active surface of the catalytic reaction is more readily available according to the above nanostructure evolution. ${ }^{[8,40]}$ Corresponding to the respond of Raman analysis, the intrinsic excellent catalytic behavior of the $\mathrm{Ni}_{3} \mathrm{~N} / \mathrm{BP}-\mathrm{AG}-1$ can be derived from this side. Lifted edges and defects facilitate the full contact of the active sites with the electrolyte, which will be attributed to the establishment of a stable heterojunction substrate of BP-AG with a special structure due to the high temperature and high pressure in the ball-milling process.

Furthermore, the superior activity of $\mathrm{Ni}_{3} \mathrm{~N} / \mathrm{BP}-\mathrm{AG}-1$ can be understood via examinations of stability and durability. Here, in Figure $6 \mathrm{a}, \mathrm{Ni}_{3} \mathrm{~N} / \mathrm{BP}-\mathrm{AG}-1$ is evaluated by chronoamperometry in the $1 \mathrm{~m} \mathrm{KOH}$ solution with a constant potential of $233 \mathrm{mV}$ which is equal to the overpotential. The curve that symbolized

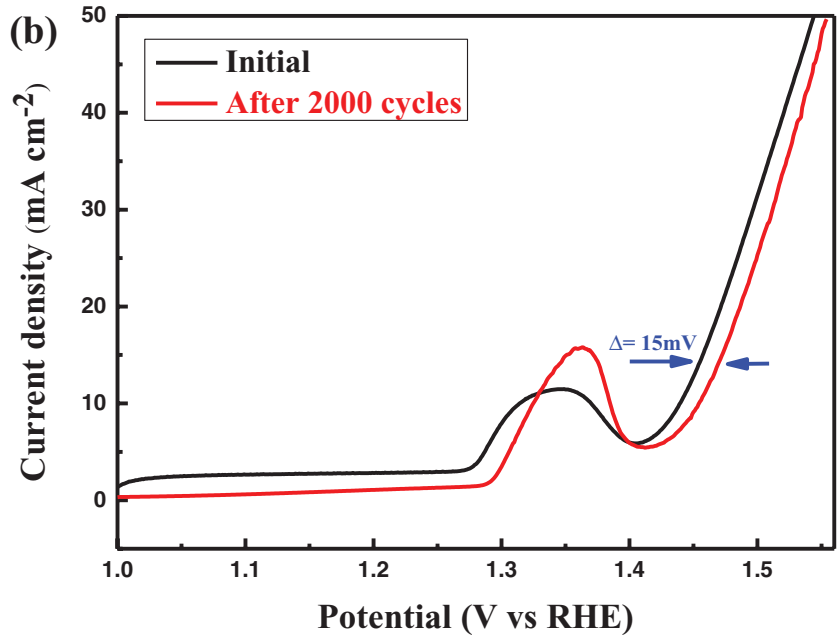

Figure 6. a) $1-t$ curve obtained for OER with the $\mathrm{Ni} i_{3} \mathrm{~N} / \mathrm{BP}-\mathrm{AG}-1$ at $233 \mathrm{mV}$ and b) polarization curves of the $\mathrm{Ni} \mathrm{i}_{3} \mathrm{~N} / \mathrm{BP}-\mathrm{AG}-1$ recorded before and after 2000 cycles, scan rate: $50 \mathrm{mV} \mathrm{s}^{-1}$. 
the alteration of current density along with reaction time basically remained unchanged after a $10000 \mathrm{~s}$ long continuous operation. It is noting that there is a transitory process of current density dropping that appeared at the beginning of durability tests. The deactivation of current density might charge upon the oxidation on the surface of the partial BP component, which would be contaminated readily under the oxygenenriched condition. Even then, the $\mathrm{Ni}_{3} \mathrm{~N} / \mathrm{BP}-\mathrm{AG}-1$ catalyst still shows good electrochemical durability. The initial current density remains over $86.4 \%$ after $10000 \mathrm{~s}$, which is better than other ratios (Figure S6b, Supporting Information). Moreover, the stability of the as-prepared $\mathrm{Ni}_{3} \mathrm{~N} / \mathrm{BP}-\mathrm{AG}-1$ is illustrated in Figure 6b. After 2000 continuous CV cycles at a scanning rate of $50 \mathrm{mV} \mathrm{s}^{-1}$, negligible activity loss about $15 \mathrm{mV}$ was observed, further confirming its possibility of widespread application.

All tests prove that the ratio of 1:1:1 is optimal among three projects, which might attribute to the best retention of $\mathrm{Ni}_{3} \mathrm{~N}$ during the ball-milling process. By contrast, the representative peak located at $853.2 \mathrm{eV}$ cannot be clearly observed in both $\mathrm{Ni}_{3} \mathrm{~N} / \mathrm{BP}-\mathrm{AG}-2$ and $\mathrm{Ni}_{3} \mathrm{~N} / \mathrm{BP}-\mathrm{AG}-0.5$, particularly on the latter (Figure S7a,b, Supporting Information). Unusually, the peaks around $870.9 \mathrm{eV}$ can be consistent with the high-resolution $\mathrm{Ni}$ $2 \mathrm{p}$ spectra of $\mathrm{Ni}_{3} \mathrm{~N} / \mathrm{BP}-\mathrm{AG}-2$, which is identified the symbol of metal Ni. Hence, partial $\mathrm{Ni}_{3} \mathrm{~N}$ particles might be reduced to metal Ni because of the high pressure and temperature, which were generated by the drastic impact. And this impact may induce the fracture of $\mathrm{Ni}-\mathrm{N}$ bonds or the phase transformation which resulted in unremarkable electrocatalytic performances of $\mathrm{Ni}_{3} \mathrm{~N} / \mathrm{BP}-\mathrm{AG}-2$. And the TEM images (Figure S8a,b, Supporting Information) of $\mathrm{Ni}_{3} \mathrm{~N} / \mathrm{BP}-\mathrm{AG}-2$ coordinated with the XPS analysis. According to Figure S8 in the Supporting Information, the sporadic $\mathrm{Ni}_{3} \mathrm{~N}$ particles were disappeared and substituted by a wide range of black bulk. And the entire area became almost opaque. In Figure S8c in the Supporting Information, partial $\mathrm{Ni}_{3} \mathrm{~N}$ particles of $\mathrm{Ni}_{3} \mathrm{~N} / \mathrm{BP}-\mathrm{AG}-0.5$ are aggregated. As is known to all, the generation of unsaturated active sites might be fabricated in the course of mechanical exfoliation due to the amplifying defects of BP. Thus, the electrocatalytic performances of $\mathrm{Ni}_{3} \mathrm{~N} / \mathrm{BP}-\mathrm{AG}-2$ with skimp effective active sites have nothing on $\mathrm{Ni}_{3} \mathrm{~N} / \mathrm{BP}-\mathrm{AG}-1$.

\section{Conclusion}

In summary, the $\mathrm{Ni}_{3} \mathrm{~N}$ supported on BP-AG heterostructure hybrids as an easy to implement and low-cost electrocatalyst for OER was successfully fabricated. First, the steady BP-AG heterostructure depends on the strong $\mathrm{P}-\mathrm{C}$ bonds was gained via a handy mechanical ball-milling method. The formation of Ni-P bonds reflected the junction between metal and semiconductor might dramatically improve the reaction rate. And because of the Ni atoms partially oxidized, the nice activity of $\mathrm{Ni}_{3} \mathrm{~N} / \mathrm{BP}-\mathrm{AG}-1$ may be ascribed to the formation of $\mathrm{NiOOH}$ layers in OER process and the special interface between $\mathrm{NiO}$ and $\mathrm{Ni}_{3} \mathrm{~N}$. The as-prepared $\mathrm{Ni}_{3} \mathrm{~N} / \mathrm{BP}-\mathrm{AG}-1$ exhibited agreeable electrocatalytic activity for OER in alkaline condition. The $\mathrm{Ni}_{3} \mathrm{~N} / \mathrm{BP}-\mathrm{AG}-1$ electrode was able to risk a current density of $10 \mathrm{~mA} \mathrm{~cm}^{-2}$ at overpotentials of $233 \mathrm{mV}$. Similarly, Tafel slope

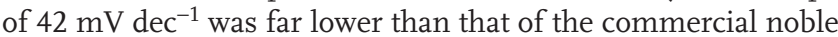

metal catalyst, too. In addition, the doping effect of $\mathrm{N}$ atoms cannot be ignored. What is noteworthy is that the property of $\mathrm{Ni}_{3} \mathrm{~N} / \mathrm{BP}-\mathrm{AG}-1$ is the best just at present, while that of $\mathrm{Ni}_{3} \mathrm{~N} /$ BP-AG-0.5 is nearby. Considering this aspect, the existence of more satisfying synthesis recipe may be verified in the near future. Therefore, a lot of windows could be the next door to further enhance the utility value of $\mathrm{Ni}_{3} \mathrm{~N} / \mathrm{BP}-\mathrm{AG}$ hybrids.

\section{Experimental Section}

Chemicals: Graphene powder (physical methods, size: $0.5-5 \mu \mathrm{m}$, thickness: $1-2 \mathrm{~nm}$, single-layer ratio: $\approx 80 \%$ ) was purchased from Nanjing XFNANO Materials Tech Co., Ltd. Red phosphorus $(99.999 \%$ metals basis, $1-5 \mathrm{~mm}$ ) and nickel chloride hexahydrate $(99.999 \%$ metals basis) were used. Nafion solution ( $5 \mathrm{wt} \%$ ) was purchased from Shanghai Geshi Energy Technology Co., Ltd. Isopropyl alcohol (gas chromatography (CC) grade, $\geq 99.9 \%$ ) was used. The chemicals were all used as obtained without any purification.

Material Synthesis-Preparation of BP Nanosheets: BP was obtained via straightway ball-milling RP under an argon atmosphere. Briefly, $2 \mathrm{~g}$ of RP was added into a $25 \mathrm{~mL}$ Teflon-lined stainless-steel autoclave with $17.5 \mathrm{~mL}$ of deionized water (DI). Then, the hydrothermal process occurred at $180^{\circ} \mathrm{C}$ for $20 \mathrm{~h}$ to remove the surface oxidation drastically. Followed, the dry RP particles were ground into a pristine powder. Followed, about $1.6 \mathrm{~g}$ of the surplus pristine RP powder and number of stainless-steel balls which contain different specifications were added into a stainless-steel jar with a capacity of $50 \mathrm{~cm}^{3}$. The ball-milling project has proceeded under an argon-saturated condition for $48 \mathrm{~h}$ with a rotation speed of $500 \mathrm{r} \mathrm{min}^{-1}$. Peculiarly, the transformed BP was keeping under the argon protection for later use.

Material Synthesis-Activation of Commercial Pristine Graphene Nanosheets: AG was produced from the etched graphene powder. At first, the graphene powder was submerged in $60 \mathrm{~mL}$ of $6 \mathrm{M} \mathrm{KOH}$ aqueous solution and stirred for $12 \mathrm{~h}$ to ensure the full contact between graphene and background. Next, the graphene was centrifuged and dried in a vacuum oven at $70{ }^{\circ} \mathrm{C}$ overnight. After simple trituration, the graphene was treated at $800{ }^{\circ} \mathrm{C}$ for $2 \mathrm{~h}$ with the heating rate of $2{ }^{\circ} \mathrm{C} \mathrm{min}-1$ under flowing $\mathrm{N}_{2}$ gas. And then, the graphene was naturally cooled to room temperature.

Material Synthesis-Synthesis of $\mathrm{Ni}_{3} \mathrm{~N}$ Particles: In the beginning, $0.594 \mathrm{~g}$ of $\mathrm{NiCl}_{2} \cdot 6 \mathrm{H}_{2} \mathrm{O}, 0.185 \mathrm{~g}$ of $\mathrm{NH}_{4} \mathrm{~F}$, and $0.75 \mathrm{~g}$ of urea were dissolved in $70 \mathrm{~mL} \mathrm{DI}$. In the next, the mixed solution was transferred into a $100 \mathrm{~mL}$ Teflon-lined stainless-steel autoclave and subjected to hydrothermal reaction conditions at $120{ }^{\circ} \mathrm{C}$ for $4 \mathrm{~h}$ to form the procedure. The product was separated by centrifugation and washed with $\mathrm{DI}$ and ethanol for several times. Afterward, the procedure was dried in a vacuum oven at $80^{\circ} \mathrm{C}$ for $12 \mathrm{~h}$. The collected solid powder was then placed in a tube furnace and heated to $250^{\circ} \mathrm{C}$ for $2 \mathrm{~h}$ under air. Finally, the procedure was maintained in $\mathrm{NH}_{3}$ atmosphere and heated to $380^{\circ} \mathrm{C}$ for $2 \mathrm{~h}$.

Material Synthesis-Fabrication of BP-AG and $\mathrm{Ni}_{3} \mathrm{~N} / \mathrm{BP}-\mathrm{AG}$ : For fabricating the BP-AG, $100 \mathrm{mg}$ of $\mathrm{BP}, 100 \mathrm{mg}$ of $\mathrm{AG}$, and appropriate balls were thrown into the jar that as same as the jar used in previously experiment. At the same time, the argon gas enclosed unremittingly into the jar to protect the BP nanosheets for $30 \mathrm{~min}$. After milling for $48 \mathrm{~h}$ with a rotation speed of $800 \mathrm{r} \mathrm{min}^{-1}$, the BP-AG compounds were conserved in the jar with engorged argon gas.

Furthermore, the $\mathrm{Ni}_{3} \mathrm{~N} / \mathrm{BP}-\mathrm{AG}$ with different synthesis formula could be obtained via changing the additive mass of $\mathrm{Ni}_{3} \mathrm{~N}$. Herein, 200, 100, and $50 \mathrm{mg}$ of as-prepared $\mathrm{Ni}_{3} \mathrm{~N}$ were added into jars $\left(800 \mathrm{r} \mathrm{min}^{-1}\right.$, $48 \mathrm{~h}$ ), respectively. At last, the $\mathrm{Ni}_{3} \mathrm{~N} / \mathrm{BP}-\mathrm{AG}-2, \mathrm{Ni}_{3} \mathrm{~N} / \mathrm{BP}-\mathrm{AG}-1$, and $\mathrm{Ni}_{3} \mathrm{~N} / \mathrm{BP}-\mathrm{AG}-0.5$ were gained and storage in the argon-saturated bottle.

Electrocatalytic Measurement: The electrochemical tests of the samples were evaluated in a typical three-electrode systems on a CHI660E electrochemical workstation. The prepared catalysts were 
directly used as a working electrode. A graphite rod electrode and an $\mathrm{Ag} / \mathrm{AgCl}$ electrode were used as the counter electrode and reference electrode, respectively. All samples were prepared by adding $5 \mathrm{mg}$ of the catalyst into $1 \mathrm{~mL}$ of solution which consist of $800 \mu \mathrm{L}$ of isopropyl alcohol, $170 \mu \mathrm{L}$ of $\mathrm{H}_{2} \mathrm{O}$ and $30 \mu \mathrm{L}$ of $5 \%$ Nafion solution, followed by ultrasonication for $1 \mathrm{~h}$ to form the homogeneous inks. Then, $10 \mu \mathrm{L}$ of sample ink was warily dropped onto the smooth glassy carbon rotating disk electrode. The LSV and stabilization tests were investigated in $\mathrm{O}_{2}$-saturated $1.0 \mathrm{M} \mathrm{KOH}$.

Material Characterization: XRD characterization data were collected by using a Bruker D8 advance. Raman spectrum was carried out on a Thermo ESCALAB 250 system with a LabRAM HR Evolution $(\lambda=633 \mathrm{~nm})$. TEM images were gained on a JEOL JEM-2100F. AFM images were measured by an Agilent 5500AFM. XPS measurements were performed on a Kratos Axis UltraDLD with Al- $K_{\alpha}$ X-ray $(1486.6 \mathrm{eV})$ radiation.

\section{Supporting Information}

Supporting Information is available from the Wiley Online Library or from the author.

\section{Acknowledgements}

This work was supported by the National Natural Science Foundation of China (NSFC) (Grant Nos. 91745112 and 21671133) and Science and Technology Commission of Shanghai Municipality (18020500800). This work was also sponsored by Shanghai Rising-Star Program (19QA1404100).

\section{Conflict of Interest}

The authors declare no conflict of interest.

\section{Keywords}

black phosphorus, graphene, heterostructures, nickel nitride, oxygen evolution reaction

Received: March 24, 2019

Revised: May 3, 2019

Published online: June 24, 2019

[1] Z. Zhang, D. Zhou, J. Liao, X. Bao, H. Yu, Int. J. Energy Res. 2019, $43,1460$.

[2] Z. Xie, H. Tang, Y. Wang, ChemElectroChem 2019, 6, 1206.

[3] Y. Gong, Z. Xu, H. Pan, ChemistrySelect 2019, 4, 1131.

[4] J. Zhu, D. Yang, Z. Yin, Q. Yan, H. Zhang, Small 2014, 10, 3480.

[5] M. Wang, M. Lin, J. Li, L. Huang, Z. Zhuang, C. Lin, L. Zhou, L. Mai, Chem. Commun. 2017, 53, 8372.

[6] Y. Fan, S. Ida, A. Staykov, T. Akbay, H. Hagiwara, J. Matsuda, K. Kaneko, T. Ishihara, Small 2017, 13, 1700099.

[7] L. L. Feng, G. D. Li, Y. Liu, Y. Wu, H. Chen, Y. Wang, Y. C. Zou, D. Wang, X. Zou, ACS Appl. Mater. Interfaces 2015, 7, 980.

[8] J. Su, G.-D. Li, X.-H. Li, J.-S. Chen, Adv. Sci. 2019, 6, 1801702.

[9] X. Ren, J. Zhou, X. Qi, Y. Liu, Z. Huang, Z. Li, Y. Ge, S. C. Dhanabalan, J. S. Ponraj, S. Wang, J. Zhong, H. Zhang, Adv. Energy Mater. 2017, 7, 1700396.
[10] J. Wang, D. Liu, H. Huang, N. Yang, B. Yu, M. Wen, X. Wang, P. K. Chu, X. F. Yu, Angew. Chem., Int. Ed. 2018, 57, 2600.

[11] R. J. Wu, M. Topsakal, T. Low, M. C. Robbins, N. Haratipour, J. S. Jeong, R. M. Wentzcovitch, S. J. Koester, K. A. Mkhoyan, J. Vac. Sci. Technol., A 2015, 33, 060604.

[12] L. Li, Y. Yu, G. J. Ye, Q. Ge, X. Ou, H. Wu, D. Feng, X. H. Chen, Y. Zhang, Nat. Nanotechnol. 2014, 9, 372.

[13] R. Gusmão, Z. Sofer, M. Pumera, Angew. Chem., Int. Ed. 2017, 56, 8052.

[14] H. Liu, Y. Du, Y. Deng, P. D. Ye, Chem. Soc. Rev. 2015, 44, 2732.

[15] Z. Shen, S. Sun, W. Wang, J. Liu, Z. Liu, J. C. Yu, J. Mater. Chem. A 2015, 3, 3285.

[16] M. Zhu, S. Kim, L. Mao, M. Fujitsuka, J. Zhang, X. Wang, T. Majima, J. Am. Chem. Soc. 2017, 139, 13234.

[17] Q. Jiang, L. Xu, N. Chen, H. Zhang, L. Dai, S. Wang, Angew. Chem., Int. Ed. 2016, 55, 13849

[18] D. Gao, J. Zhang, T. Wang, W. Xiao, K. Tao, D. Xue, J. Ding, J. Mater. Chem. A 2016, 4, 17363.

[19] T. Liu, M. Li, C. Jiao, M. Hassan, X. Bo, M. Zhou, H.-L. Wang, J. Mater. Chem. A 2017, 5, 9377.

[20] S. Nandi, S. K. Singh, D. Mullangi, R. Illathvalappil, L. George, C. P. Vinod, S. Kurungot, R. Vaidhyanathan, Adv. Energy Mater. 2016, 6, 1601189 .

[21] L. Han, K. Feng, Z. Chen, Energy Technol. 2017, 5, 1908.

[22] T. Wu, Y. Ma, Z. Qu, J. Fan, Q. Li, P. Shi, Q. Xu, Y. Min, ACS Appl. Mater. Interfaces 2019, 11, 5136.

[23] K. Xu, P. Chen, X. Li, Y. Tong, H. Ding, X. Wu, W. Chu, Z. Peng, C. Wu, Y. Xie, J. Am. Chem. Soc. 2015, 137, 4119.

[24] T. Wu, J. Fan, Q. Li, P. Shi, Q. Xu, Y. Min, Adv. Energy Mater. 2018, 8, 1701799 .

[25] G. Abellan, S. Wild, V. Lloret, N. Scheuschner, R. Gillen, U. Mundloch, J. Maultzsch, M. Varela, F. Hauke, A. Hirsch, J. Am. Chem. Soc. 2017, 139, 10432.

[26] F. Shi, Z. Geng, K. Huang, Q. Liang, Y. Zhang, Y. Sun, J. Cao, S. Feng, Adv. Sci. 2018, 5, 1800575.

[27] A. C. Crowther, A. Ghassaei, N. Jung, L. E. Brus, ACS Nano 2012 , 6, 1865.

[28] J. Hassoun, F. Bonaccorso, M. Agostini, M. Angelucci, M. G. Betti, R. Cingolani, M. Gemmi, C. Mariani, S. Panero, V. Pellegrini, B. Scrosati, Nano Lett. 2014, 14, 4901.

[29] M. Zhu, Z. Sun, M. Fujitsuka, T. Majima, Angew. Chem., Int. Ed. 2018, 57, 2160 .

[30] L.-A. Stern, L. Feng, F. Song, X. Hu, Energy Environ. Sci. 2015, 8, 2347.

[31] J. Huang, Y. Sun, X. Du, Y. Zhang, C. Wu, C. Yan, Y. Yan, G. Zou, W. Wu, R. Lu, Y. Li, J. Xiong, Adv. Mater. 2018, 30, 1803367.

[32] X. Lu, L. Gu, J. Wang, J. Wu, P. Liao, G. Li, Adv. Mater. 2017, 29, 1604437.

[33] X. Bai, Q. Wang, G. Xu, Y. Ning, K. Huang, F. He, Z. J. Wu, J. Zhang, Chem. - Eur. J. 2017, 23, 16862.

[34] Y. Sun, T. Zhang, X. Li, Y. Bai, X. Lyu, G. Liu, W. Cai, Y. Li, Adv. Mater. Interfaces 2018, 5, 1800473.

[35] D. Ding, K. Shen, X. Chen, H. Chen, J. Chen, T. Fan, R. Wu, Y. Li, ACS Catal. 2018, 8, 7879

[36] Y. Pan, K. Sun, S. Liu, X. Cao, K. Wu, W. C. Cheong, Z. Chen, Y. Wang, Y. Li, Y. Liu, D. Wang, Q. Peng, C. Chen, Y. Li, J. Am. Chem. Soc. 2018, 140, 2610.

[37] N. Wang, L. Li, D. Zhao, X. Kang, Z. Tang, S. Chen, Small 2017, 13, 1701025.

[38] Y. Shi, Y. Yu, Y. Liang, Y. Du, B. Zhang, Angew. Chem., Int. Ed. 2019, $58,3769$.

[39] M. B. Stevens, L. J. Enman, A. S. Batchellor, M. R. Cosby, A. E. Vise, C. D. M. Trang, S. W. Boettcher, Chem. Mater. 2017, 29, 120.

[40] A. Wu, Y. Xie, H. Ma, C. Tian, Y. Gu, H. Yan, X. Zhang, G. Yang, H. Fu, Nano Energy 2018, 44, 353. 